\title{
O "Coro dos Contrários" em White on white de György Ligeti: \\ Aspectos da organização formal
}

Lourdes Saraiva

Este artigo focaliza o primeiro estudo do volume três, White on white, de György Ligeti, e tem como objetivo explorar os parâmetros responsáveis pela organização da forma bem como abordar as possibilidades de confluências de princípios composicionais utilizados neste estudo com outras obras. Esta investigação representa uma abordagem inicial e pretende ser aprofundada em um segundo momento desta pesquisa.

\section{Dos Estudos para Piano}

Em 1985 György Ligeti, então com 61-62 anos, começa a compor estudos para piano que, salvo períodos de interrupção, resultam em três livros até o ano de 2001. O primeiro livro compreende os estudos Désordre, Cordes à vide, Touches bloquées, Fanfares, Arc-en-ciel e, Automne à Varsovie, os quais, em 1986, conquistam o prêmio Grawemeyer as Universidade de Louisville - Kentucky (Ligeti, 1986, p.3). Após dois anos da conclusão do primeiro livro de estudos, Ligeti inicia a produção do segundo livro que resulta nos estudos Galamb Borong (1988), Fém (1989), Vertige (1990), Der Zauberlehrling (1994), En suspens (1994), Entrelacs (1993), L'escalier du diable (1993) e Coloana infinită (1993). O terceiro e último livro, “derradeira obra” (CHAVES, 2006, p.86) da vida do compositor, compreende quatro estudos: White on White (1995), Pour Irina (1996-1997), À bout de souffle (1997) e Canon (2001).

Segundo Chaves "esses livros representam, juntamente com a obra pianística de Olivier Messiaen, a contribuição mais significativa de um compositor da segunda metade do século XX à literatura do piano.” (CHAVES, 2006, p. 86). Assim, eles têm instigado intérpretes, compositores e analistas devido à sua complexidade, em termos de técnica instrumental e composicional, bem como por sua inovação do uso de novas sonoridades para a literatura pianística.

Ligeti, em conformidade à sua reconhecida personalidade composicional "poliestética", adota nos três livros de estudos os mais díspares estímulos à sua 
imaginação como pontos de partida de estruturação composicional, tais como: "Sensações tácteis das formas melódicas e de acompanhamento" de "grandes compositores que pensavam pianisticamente" como "Scarlatti, Chopin, Schumann e Debussy" (LIGETI, 1996, p.9); complexidade rítmica da "simultaneidade de simetria e assimetria" e o "pulso elementar" (LIGETI, 1996, p.9) da música africana ${ }^{1}$ como, por exemplo, em Automne à Varsovie e Désordre; "forma de pensar em termos de padrões de movimento" e a "possibilidade de colher configurações melódico-rítmica ilusórias ouvidas, mas não tocadas - a partir da combinação de duas ou mais vozes reais (análogas às perspectivas do impossível de Mauritz Escher)" (LIGETI, 1996, p.10); a "geometria (deformações de padrões da topologia e formas auto similares da geometria fractal)" (LIGETI, 1996, p.11); “a complexidade rítmica e métrica dos estudos para piano mecânico de Conlon Nancarrow" (LIGETI, 1996, p.11); e, “o pianismo do jazz”, "sobretudo com Thelonious Monk e Bill Evans no estudo Arc-em-ciel" (LIGETI, 1996, p.11);

\section{Sobre White on white e as divisões de orientação da partitura}

White on White foi comissionado a Ligeti pelo Royal Conservatory, Den Haag. O nome do estudo é uma metáfora à abrangência do uso das teclas brancas do piano na composição. Segundo Ligeti (1996, p. 12):

\footnotetext{
"Com White on white eu comecei o terceiro livro de estudos; a peça é diatônica (quase exclusivamente teclas brancas) a ainda não tonal."”
}

Assim como em várias outras obras de diferentes períodos tais como Apparitions (1958-59), Continuum (1968), Arc-em-ciel (1985), etc., também em White on white a métrica no sentido convencional inexiste. Desta forma Ligeti indica barras pontilhadas que possuem a "mera função de orientação" (LIGETI, 1995) ao intérprete.

Nesta análise indicaremos também, apenas a título de orientação, uma numeração para cada uma das divisões de orientação indicadas por Ligeti.

\footnotetext{
${ }^{1}$ Mais especificamente os países de "Uganda, República da África Central e Malawi entre outros" (LIGETI, 1996, p.9)

2 "With White on White I begin a third book of études; the piece is diatônic (almost exclusively white keys) and yet not tonal."
} 
O estudo divide-se no plano geral em duas seções de andamentos contrastantes. No início de cada seção o compositor indica a mínima como pulso. Na seção A, de andamento lento, ocorrem quinze divisões com abrangência de figuras em mínimas. As quatorze primeiras estão agrupadas cada uma em oito mínimas (Figura 1). No entanto, na divisão quinze, com função de codetta, é projetado um rallentando escrito, através da aumentação de valores da duração de cada mínima (Figura 2) resultando em 15 pulsos de mínimas. A seção B. de andamento rápido, inclui vinte e oito divisões contendo dezesseis colcheias em cada uma. Na última divisão apresenta uma coda com sessenta e oito colcheias indicadas por divisões assimétricas (Figura 3).

Div. 1

Div. 2

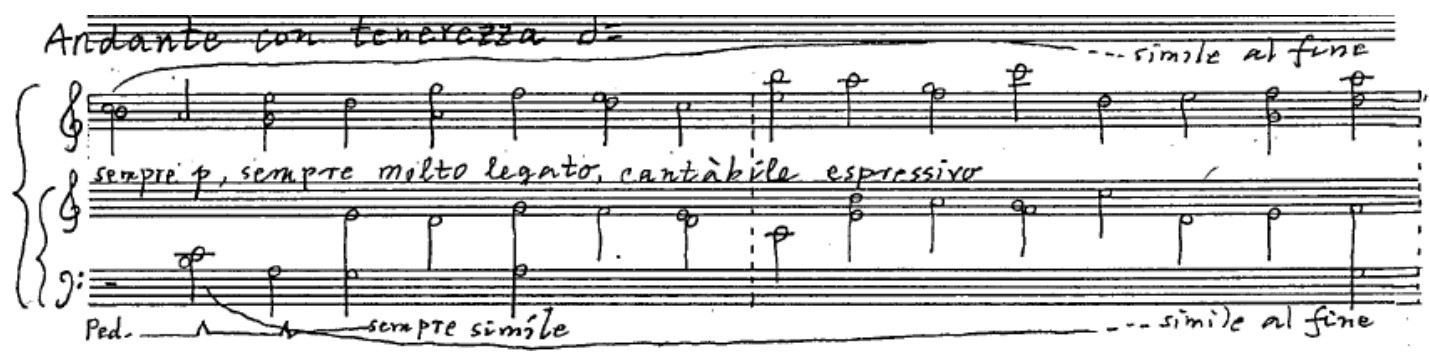

Fig. 1: Divisões 1 e 2 agrupadas em oito mínimas.

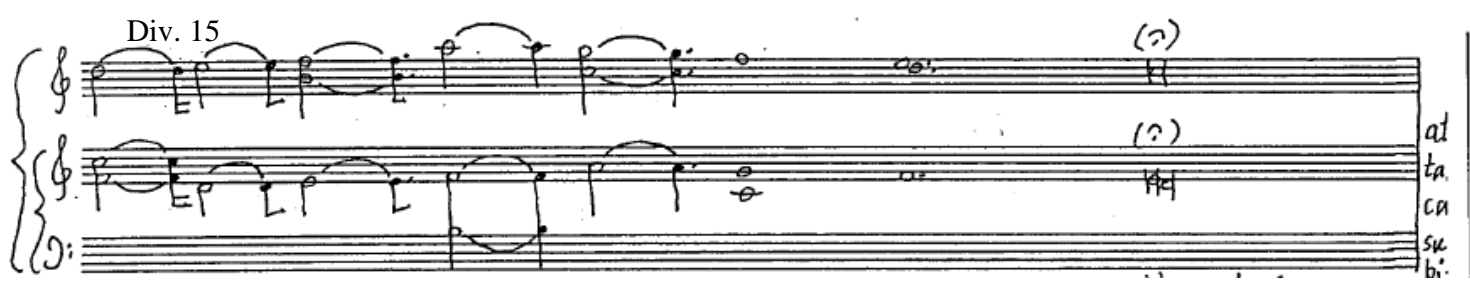

Fig. 2: Divisão 15 com acréscimo de valores em cada mínima.

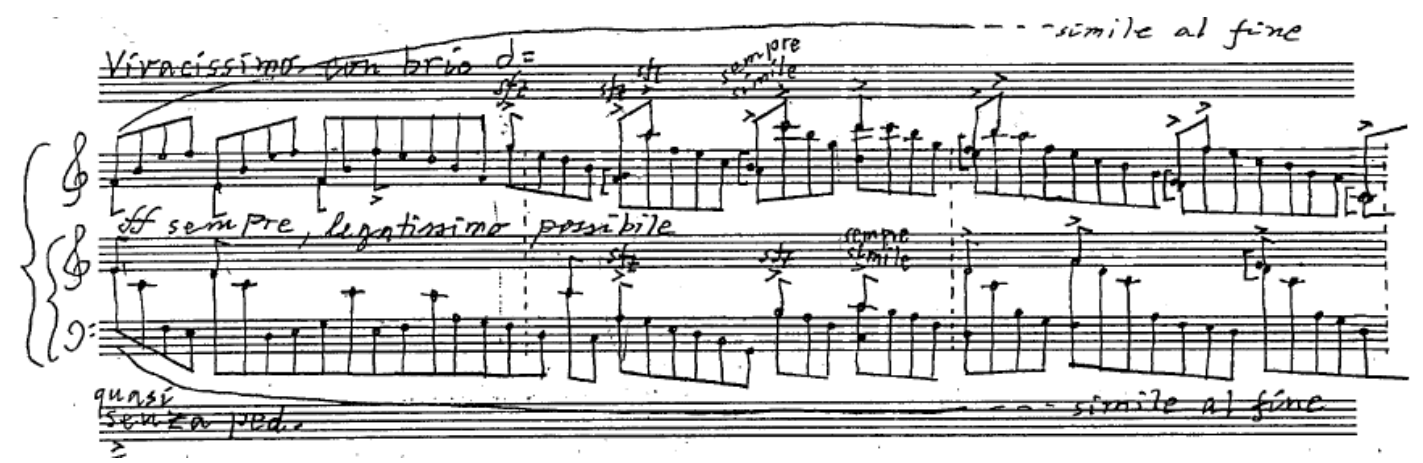

Fig.3: Início da seção B - sucessão de colcheias. 


\subsection{Aspecto formal - organização dos parâmetros estruturais}

O estudo está dividido em duas seções, com linguagem diatônica ("quase exclusivamente teclas brancas"3), notavelmente contrastantes sob vários parâmetros. O compositor utiliza técnicas composicionais distintas para cada seção.

\subsubsection{Seção A}

Na seção A, Ligeti projeta um cânon, de proporção 1:1, ou seja, "as vozes se mantêm no mesmo andamento" (COHEN, 2007, p. 60), e são projetadas em uníssono oitava abaixo na voz grave. Nesta projeção são reproduzidas exatamente as mesmas alturas da primeira voz - da primeira até a décima quinta divisão (Figura 4).

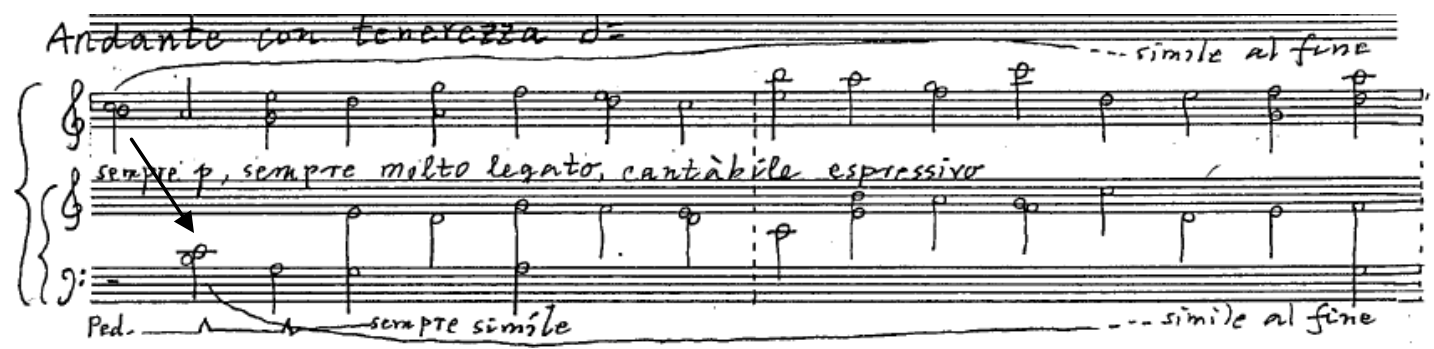

Figura 4: Cânon 1:1 - seção A.

Esta seção apresenta três subseções: a, a", a'. Cada uma delas contém cinco divisões. As seções a e a" se distinguem por ligeiras variações do desenho intervalar marcado com notas em negrito, vide Figura 5.

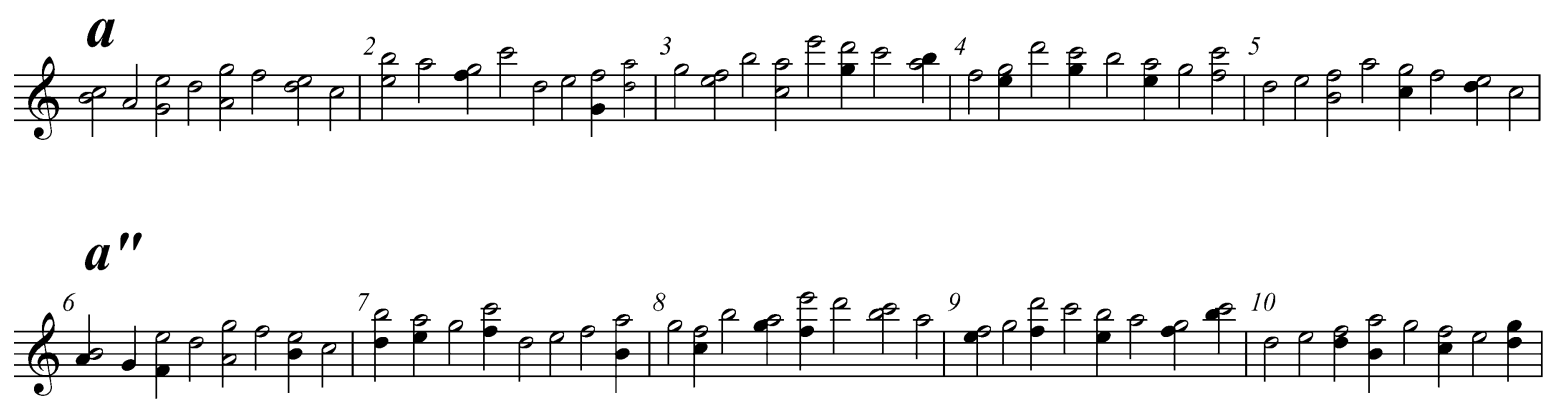

Fig. 5: Alturas diferenciais entre a subseção a e a".

Já as seções a e a' se distinguem apenas na divisão 15 por alterações de durações na forma de um rallentando escrito no final (Figura 6).

\footnotetext{
${ }^{3}$ Vide nota 2.
} 


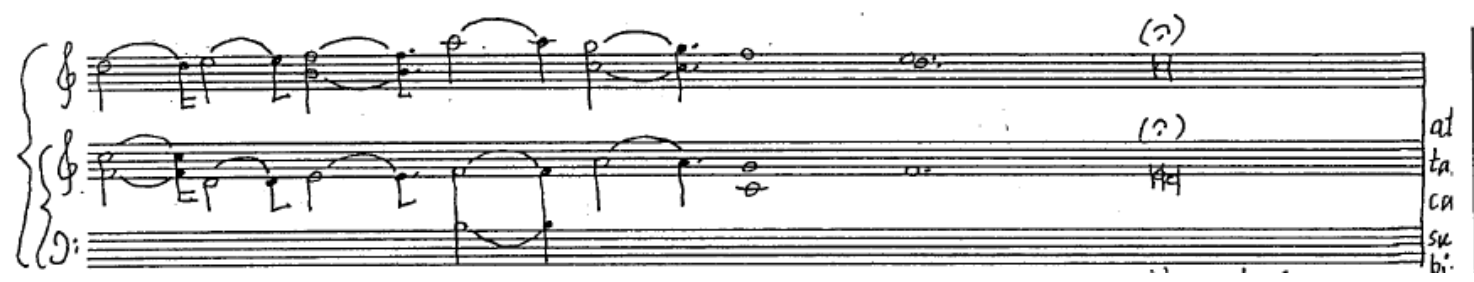

Fig. 6: Divisão 15 - rallentando escrito.

Do ponto de vista harmônico foi realizada uma redução em acordes de cada pulso em mínima. A confluência das duas vozes resultou em acordes caracterizados pela presença constante de segundas maiores ou menores, tais como: acordes em segundas de três a quatro notas, ou acordes com intervalos de segundas combinados com intervalos de quintas, quartas ou terças, ou mesmo, eventualmente, tríades e tétrades (Figura 7).

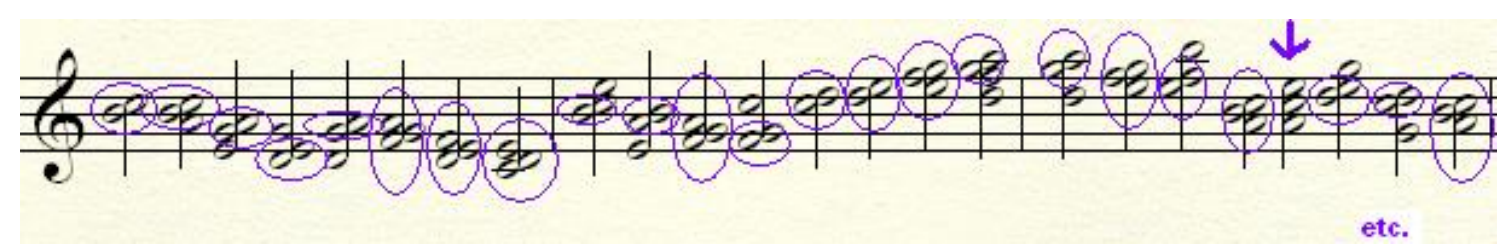

Figura 7: Redução em acordes na seção A das duas vozes.

É notável a inclusão de uma tríade de lá menor - indicada na figura 7 acima, e de uma tétrade meio-diminuta em b na divisão 15. Segundo Hicks (1993, p.173):

\footnotetext{
"Ligeti comentou que "a composição consiste principalmente na introdução de um sistema de conexões em idéias musicais ingênuas" para criar uma "rede de conexões musicalmente consistentes". Um exemplo disto é o que Ligeti chama de "sinais de intervalos" que começou a surgir em sua obra em meados de 1960. As díades e tricordes usados como sinais, diz o compositor, freqüentemente contém oitavas, quintas justas ou quartas, trítonos ou segundas maiores, mas raramente terças maiores em conexão com quintas justas, porque o desejo do compositor é evitar sons triádicos".
}

\subsubsection{Seção B}

A seção B está dividida em duas subseções que se diferenciam pelo aspecto harmônico, uso de intervalos específicos e pelo nível de dinâmica.

A primeira subseção caracteriza-se pela exclusiva presença de segundas maiores (Figura 8) e menores, na forma de intervalos harmônicos ou de acordes. Esta subseção se estende até a metade da divisão vinte e um, $327^{a}$ colcheia em dinâmica ff. A segunda 
subseção inicia na $328^{a}$ colcheia com a integração de novos intervalos na harmonia como quintas, quartas, terças e oitavas que coincidem com a dinâmica em $p p$ (Figura 9).

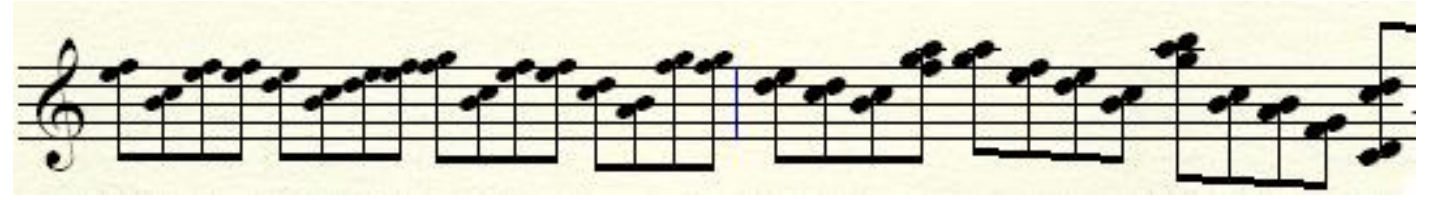

Fig. 8: Redução harmônica - início da seção B.

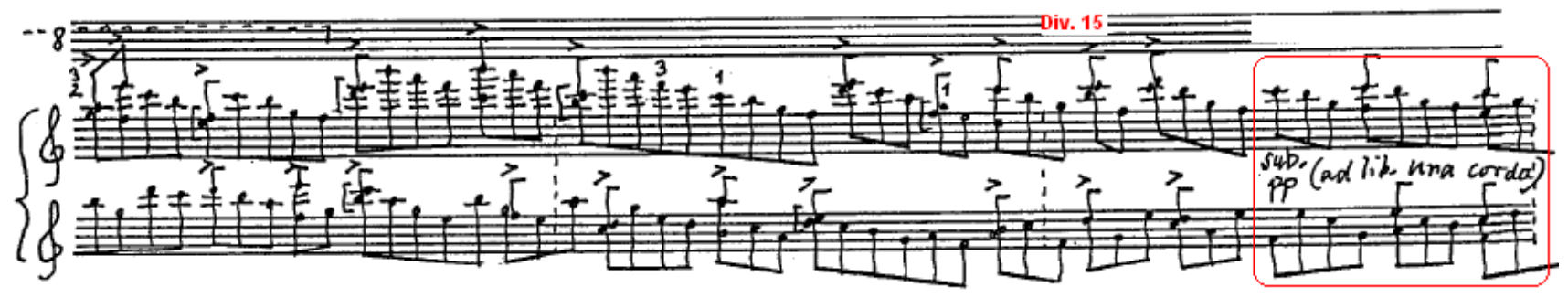

Fig.9: Divisão 15 - início da segunda subseção em vermelho, em dinâmica em pp súbito coincidindo com novos intervalos.

\subsubsection{Textura "teia de aranha"}

Em oposição à simetria plácida do cânon da seção A, a seção B apresenta uma espécie de textura polifônica extremamente complexa e projetada em uma rede de sucessões de colcheias em movimento rápido a duas vozes, que ocasionalmente se multiplicam até seis vozes. O resultado é uma "teia" ou "treliça" sonora estruturada em distintas camadas. Estas são definidas pela diversidade de acentos, contenção e expansão do registro e do movimento melódico variado.

A figura 10 ilustra o início da complexa seção B com as camadas indicadas por cores diferentes. A camada de acentos está indicada em vermelho. Os acentos estão dispostos temporalmente de maneira assimétrica e distribuídos em diferentes registros nas três pautas. As alturas desta camada formam inicialmente uma escala, F - G - G(F$A)-A-B(A)-C(B)-D(C)$, que se dilui em saltos $F(E D)-B-F-E(D)-C(B)$ etc. Em azul surge uma espécie de pedal em dó 3 entrelaçado entre as demais camadas; em verde claro há uma outra camada no registro grave em escalas ascendentes e descendentes que se contrapõe à uma outra camada similar na região aguda em lilás. $\mathrm{O}$ resultado sonoro da união destas estruturas sugere uma audição "caleidoscópica" na qual o ouvinte experiência audições plurais das interações das camadas de sons. Por 
exemplo, as notas marcadas em verde escuro (Figura 10) são percebidas como uma linha em confluência com as camadas de acentos (em vermelho). Ao mesmo tempo estas notas interagem com o pedal em dó (azul) por encontrar-se, por proximidade melódica, no registro médio. Da mesma forma o próprio movimento escalar dos acentos, mesmo rompido pelo registro expandido, é percebido como uma unidade.

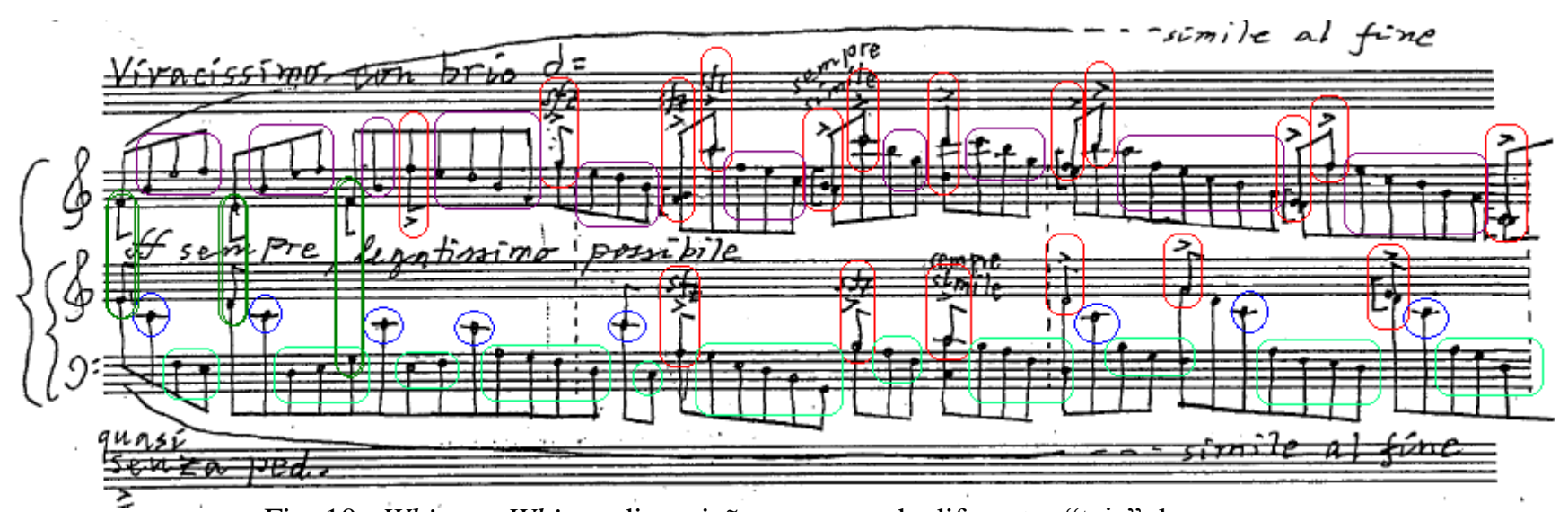

Fig. 10 : White on White - disposição em cores de diferentes "teia" de sons.

Segundo Ligeti "o que você percebe como ritmo não é o ritmo que vem da sucessão de notas que seus dedos tocam. O ritmo real da peça é uma pulsação que surge da distribuição das notas, da freqüência de suas repetições" ${ }^{\text {. }}$.

\section{A estética da teia de aranha}

O princípio de camadas sonora como uma "teia" ou "treliça" surge também em outras obras de Ligeti de estilo "piano mecânico", influência do compositor Nancarrow, tais como Continuum (1968) para cravo e Coulée (1969) para órgão. Segundo Hicks, estas peças representam uma categoria distinta no trabalho de Ligeti, nas quais padrões de alturas e intervalos se desenvolvem gradualmente e suavemente através de uma superfície que se comporta, como ele afirma "como um mecanismo preciso". Segundo Hicks "o compositor também caracteriza seu estilo mecânico em termos que são tipicamente para ele - visuais: Continuum cria um estado musical "estroboscópico", ou um estado no qual "a música é vista como se atravessasse um número de treliças superpostas" ".

Um paralelo a esses estados de ilusão perceptiva pode ser encontrado nas artes plásticas na obra de Escher, que exerceu uma importante influência em Ligeti. Um 
exemplo de ilusão ótica é visto na figura 11, uma mandala de Escher, The Path of Life III (1966), na qual é possível perceber progressões de padrões simétricos entrelaçados em diferentes planos quando o observador fixa o foco da visão no centro da imagem. Segundo Krasek (2003, p. 199), “os padrões eram as paixões de Escher, desenhos periódicos que ele chamava de "divisões regulares do plano"”, 5.

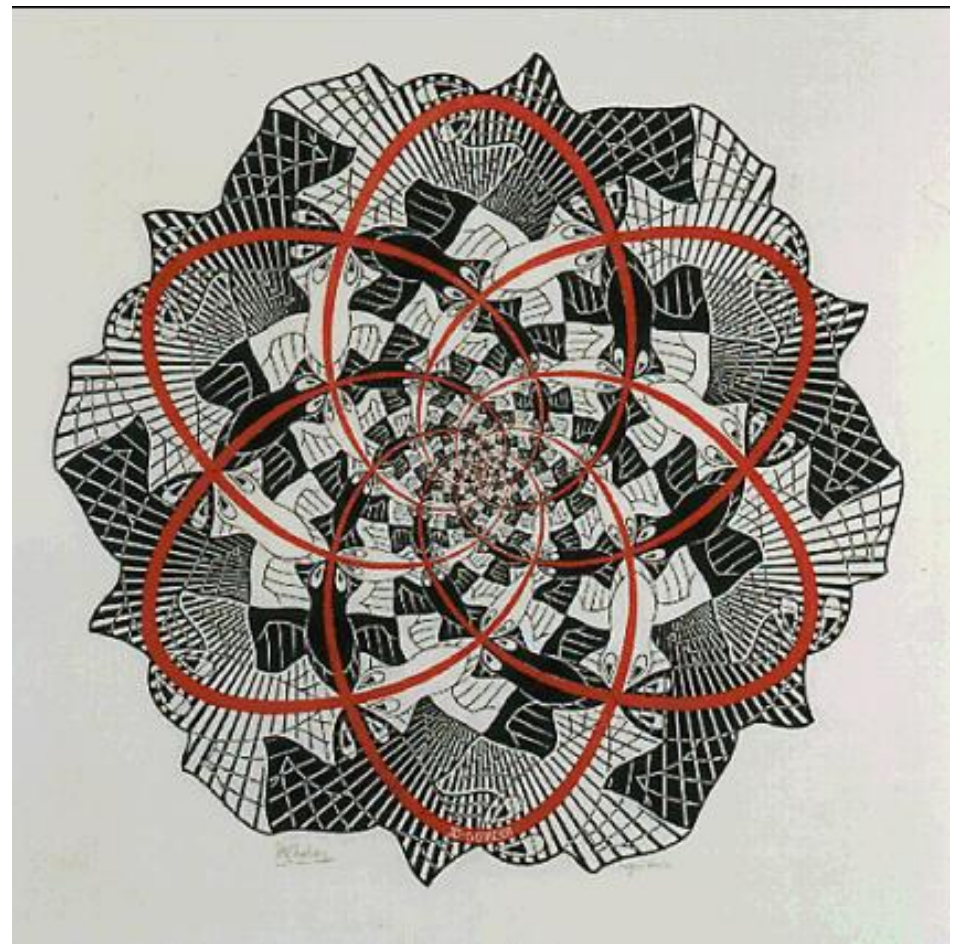

Fig. 11: Escher - Path of Life III (1966)

É significativo que em 1967, um ano antes de compor Continuum e o consequiente Coulée de 1969, e vinte e oito anos antes de compor White on White Ligeti inicia um artigo ${ }^{6}$ contando um sonho que teve na infância relacionado ao princípio composicional baseado na imagem de uma teia:

"No início de minha infância eu sonhei que não conseguia chegar até a minha pequena cama (que possuía barras que para mim significavam uma proteção) porque o quarto inteiro estava preenchido por uma teia delicada e giratória, porém densa e extremamente emaranhada, similar às secreções com os quais os bichos da seda preenchem inteiramente a sua caixa de cultura. Ao meu lado, outras criaturas vivas e objetos foram capturados nesta imensa teia: mariposas, besouros de todos os tipos, os quais tentavam chegar à fraca e trepidante vela do quarto; e travesseiros enormes, úmidos e sujos, cujos recheios

\footnotetext{
5 "Escher's passion was patterns, periodic drawings which he called "regular divisions of the plane"'.

${ }^{6}$ Ligeti, 1993, p. 164. O artigo original é de 1967 e traduzido por Jonathan W. Bernard para a revista Perspectives of New Music de 1993.
}

DAPesquisa, Florianópolis, v.3 n.5, p.772-786, 2008. 
corroídos estavam saindo pelos furos das fronhas. Cada movimento de um inseto imobilizado causava a teia toda um estremecimento de tal forma que os grandes travesseiros balançavam para trás e para frente; estes por sua vez, faziam todas as coisas se moverem ainda mais. Algumas vezes os movimentos recíprocos se tornavam tão violentos que a teia rompia em algumas partes e uns poucos besouros eram inesperadamente liberados, somente para ser capturado em seguida, com um engasgado murmúrio, no sacudir da rede novamente. Estas periódicas, e repentinos eventos ocorrentes gradualmente alteravam a estrutura interna da teia, a qual se tornava cada vez mais emaranhada. Em lugares impenetráveis nós se formavam; em outros, buracos se abriam onde tiras da teia original flutuavam como gaze. Estas transformações eram irreversíveis; nenhum estado anterior poderia ser recuperado. Há algo extremamente triste neste processo: a falta de esperança do transcorrer do tempo e do passado irrecuperável." 7

Este sonho foi de tal forma significativo que acabou influenciando o compositor na concepção de peças no final dos "anos de 1950" ${ }^{2}$. É sugestivo que este princípio tenha se estendido para várias outras obras e se transformado em maneiras tão diversas. Segundo o compositor: "o conteúdo do sonho foi muitas vezes transformado, combinado com outras idéias e processos composicionais, e manifestado somente no término de certos aspectos técnico/formais bem como no caráter geral de peças correspondentes." 9 Ligeti também afirma que sua intenção não é fazer "arte programática" e que a "identificação do conteúdo do sonho como o fundamento de algumas" de suas composições "não significam que elas sirvam como o seu conteúdo" 10

\footnotetext{
7 "In my early childhood I once dreamt that I could not make my way to my little bed (which had bars and for me signified a haven) because the whole room was filled with a finely spun but dense and extremely tangled web, similar to the secretions with which silkworms fill their entire breeding box as they pupate. Besides myself, other living creatures and objects were caught in this immense web: moths and beetles of all sorts, which were trying to get to the weakly flickering candle in the room; and enormous damp, dirty pillows, whose rotten stuffing was bulging out through rips in the covers. Every movement of an immobilized insect caused the entire web to start shaking so that the big, heavy pillows swung back and forth; this, in turn, made everything rock even more. Sometimes the reciprocal movements became so violent that the web tore in places and a few beetles were unexpectedly liberated, only to be ensnared soon thereafter, with a choked buzz, in the rocking mesh once again. These periodic, suddenly occurring events gradually altered the internal structure of the web, which became ever more tangled. In places impenetrable knots formed; in others, caverns opened up where shreds of the original web were floating about like gossamer. These transformations were irreversible; no earlier state could ever recur. There was something inexpressibly sad about this process; the hopelessness of elapsing time and of the irretrievable past."

${ }^{8}$ LIGETI, 1993, p.165. Texto original,1967.

${ }^{9}$ LIGETI, .1993, p.165.

${ }^{10}$ LIGETI, .1993, p.165.
}

DAPesquisa, Florianópolis, v.3 n.5, p.772-786, 2008. 


\section{3. "O coro dos contrários"}

White on White expressa uma estética de contrastes dramáticos, contrapondo a placidez e simetria do cânon da seção A com a assimétrica e turbulenta seção B. Ligeti escreve a divisão 15, final da seção A, como uma codetta, em rallentando escrito, com função de divisora de águas paradoxais, pois "pinta" ambos os "retratos aquáticos" com cores do mesmo espectro, os intervalos de segundas dos quais apreciava, e que ironicamente iniciam ambas as seções na forma de uma segunda menor. Paradoxal também, é que em meio à turbulência "aracnídea" da seção B o compositor subitamente tenta, de certa forma, recuperar a placidez perdida da seção A com um $p p$ súbito e justamente com a introdução do esotérico intervalo de $5^{\text {a }}$ justa, segundo intervalo da série harmônica, que irá trazer consigo um exército de intervalos variados.

A genialidade com que Ligeti consegue transformar e desenvolver estruturas musicais a partir de elementos tão simples - os seus "sinais ingênuos", em formas tão consistentes e belas podem, através da análise, viabilizar um caminho de aprendizagem composicional - que conforme enfatiza o próprio compositor: "estas são peças virtuosísticas para piano, estudos no sentido pianístico e composicional” (LIGETI, 1996, p.12).

$$
* * * * *
$$




\section{BIBLIOGRAFIA}

CHAVES, Celso Loureiro. Memórias do Pierrô lunar e outras histórias musicais. Porto Alegre: L\&PM, 2006.

COHEN, Sara. Polirritmos nos Estudos para piano de György Ligeti (Primeiro Caderno). Tese de Doutorado. Programa de Pós-Graduação Mestrado e Doutorado em Música - UNIRIO, 2007.

HICKS, Michael. "Interval and Form in Ligetis's Continuum and Coulée”. In: Perspectives of New Music. Vol. 31 n $^{\circ} 1$. Seatlle: Washington University Press, 1993. p.172-190.

KRASEK, Matjuska Teja. Sharing some common Interests of M.C.Escher. In: M.C Escher's Legacy. D. Schattschneider \& M. Emmer publishers. New York: Springer Berlin Heideberg, 2003. p.199. Disponível em: http://www.springerlink.com/content/k1t16431653q7024/.

LIGETI, György. White on White. Edição fac-símile, 1995.

Works for piano. (Encarte de CD). "György Ligeti Edition” - Sony SK 62308, v.3, 1996 p.7-12.

. "States, Events, Transformations". Tradução em inglês do texto original "Zustände, Ereignisse,Wandlungen"(1967) Jonathan W. Bernard. In: Perspectives of New Music. Vol. 31 n $^{\circ} 1$. Seatlle: Washington University Press, 1993. p.164-171.

\section{REFERÊNCIAS DISCOGRÁFICAS}

LIGETI, György. Works for piano: études, musica ricercata . Pierre-Laurent Aimard, piano. New York City: SONY, 1996. 1 disco compacto (74 min) : digital, estéreo . SK 62308.

\section{SITES}

http://www.mcescher.com/ (acessado em 23/07/2008) 


\section{PARTITURA}

ETUDE 15 : «WHITE ON WHITE» dédié à M. Étienne Courant

Commisrioned by the Royal Conservatory, Den Haas

Gysirgy Ligeti

NB. The rortical braken lines are not bar lines, they steve merdy for orientation.

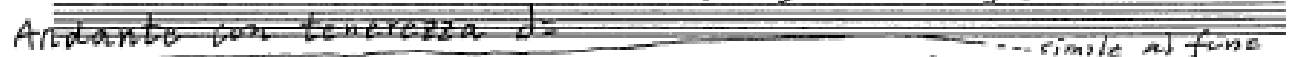
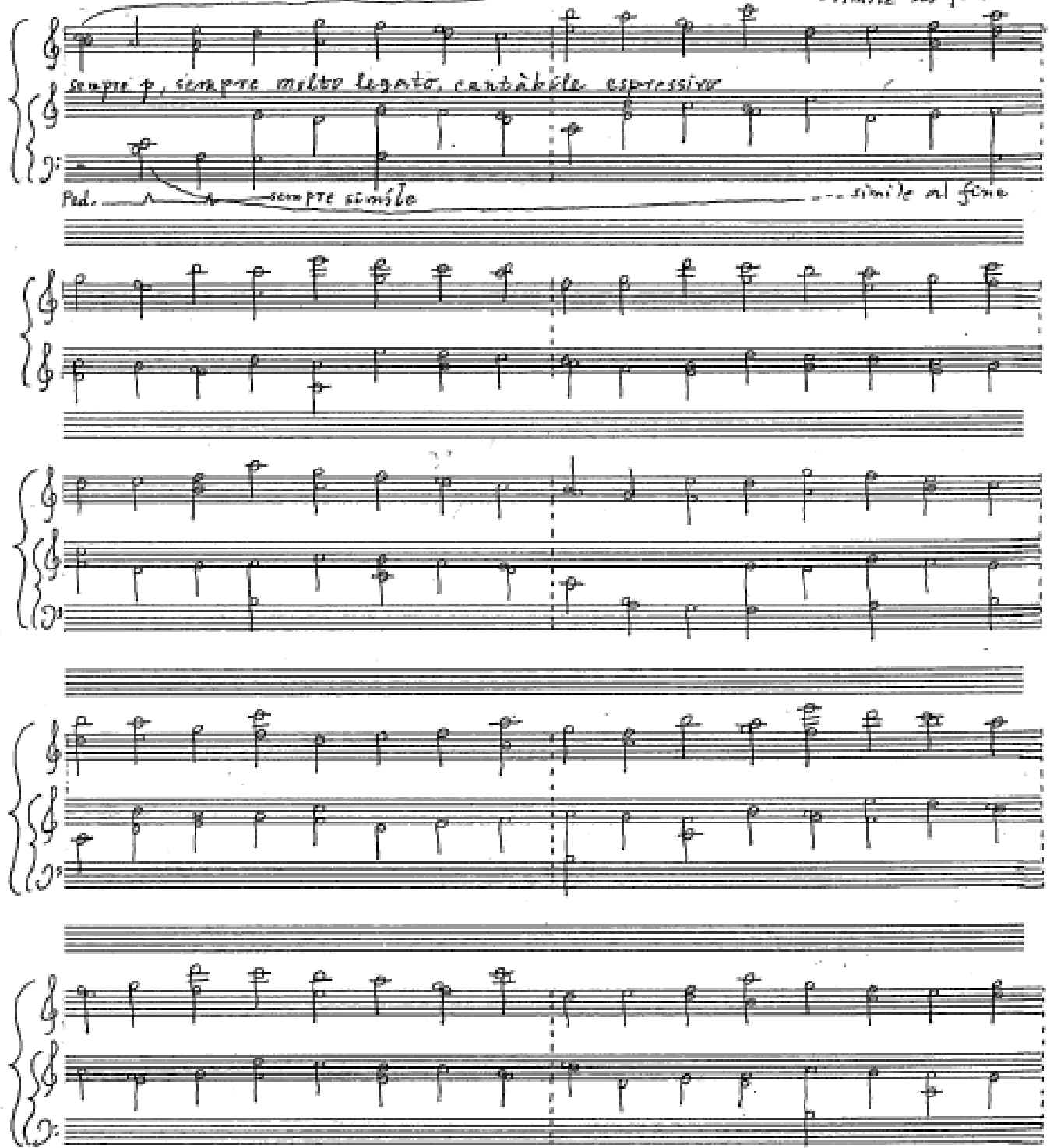

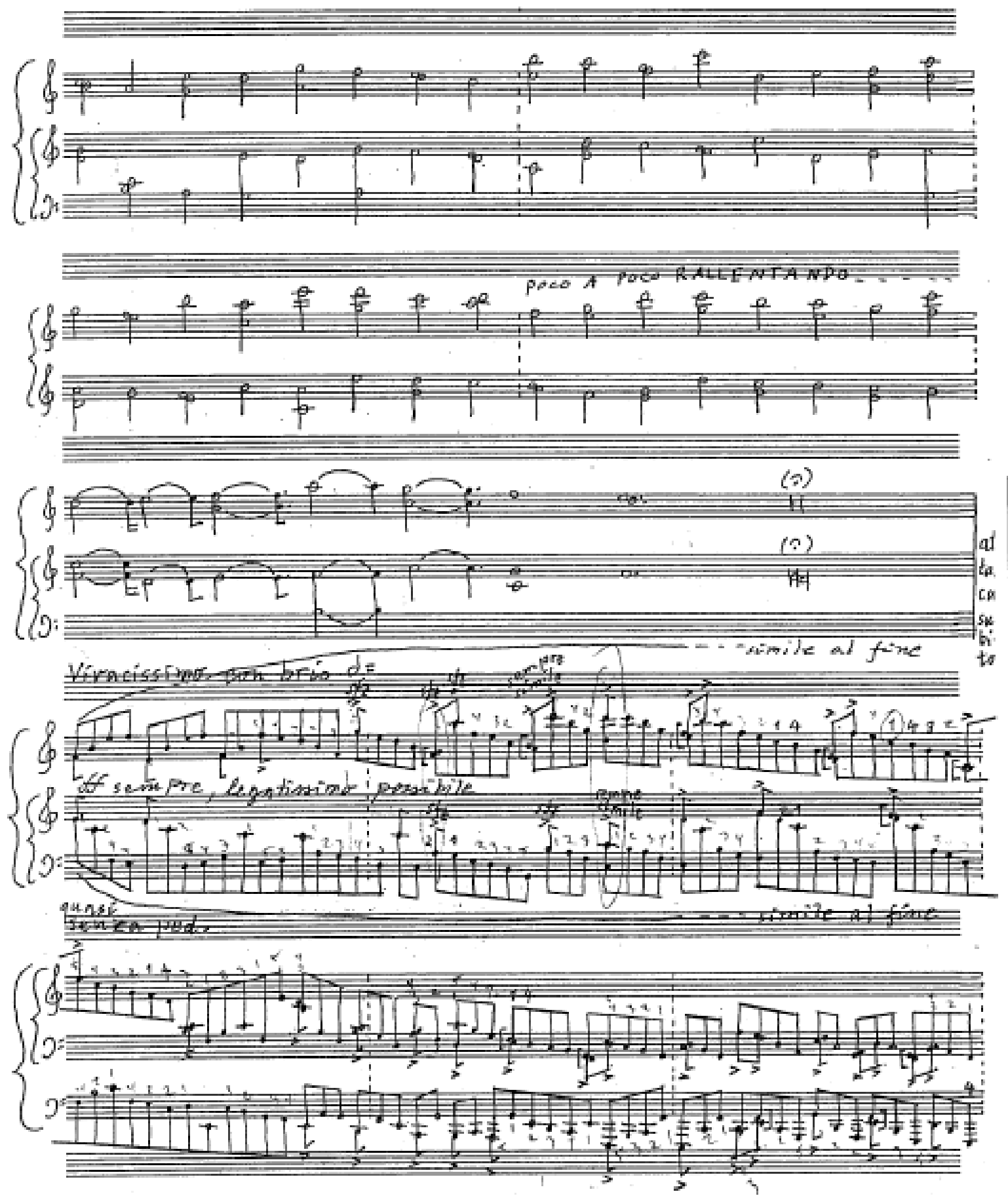

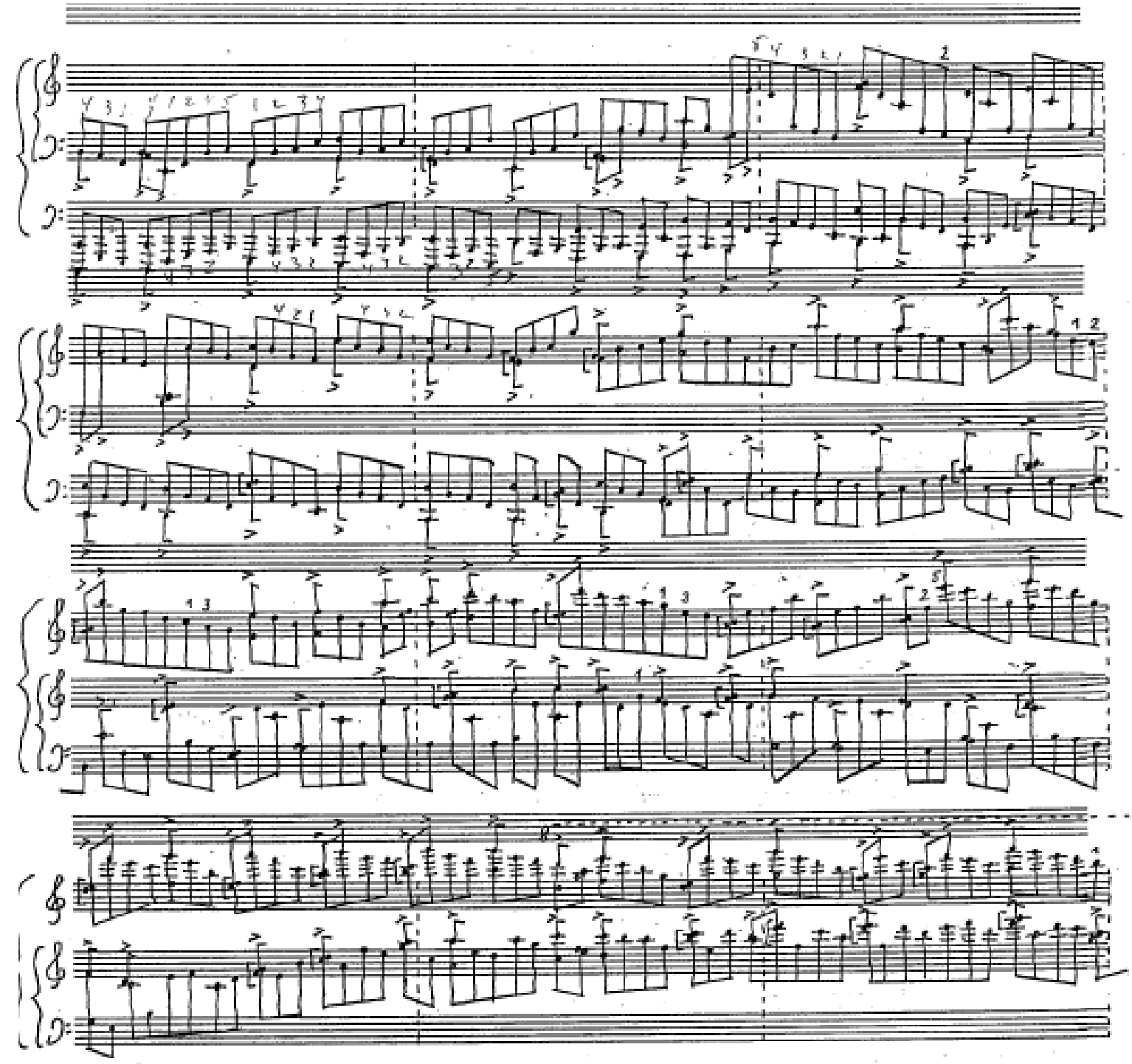

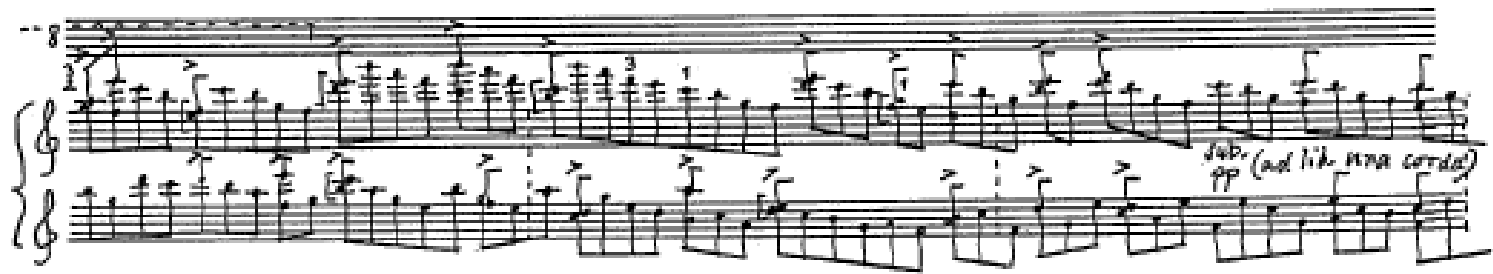



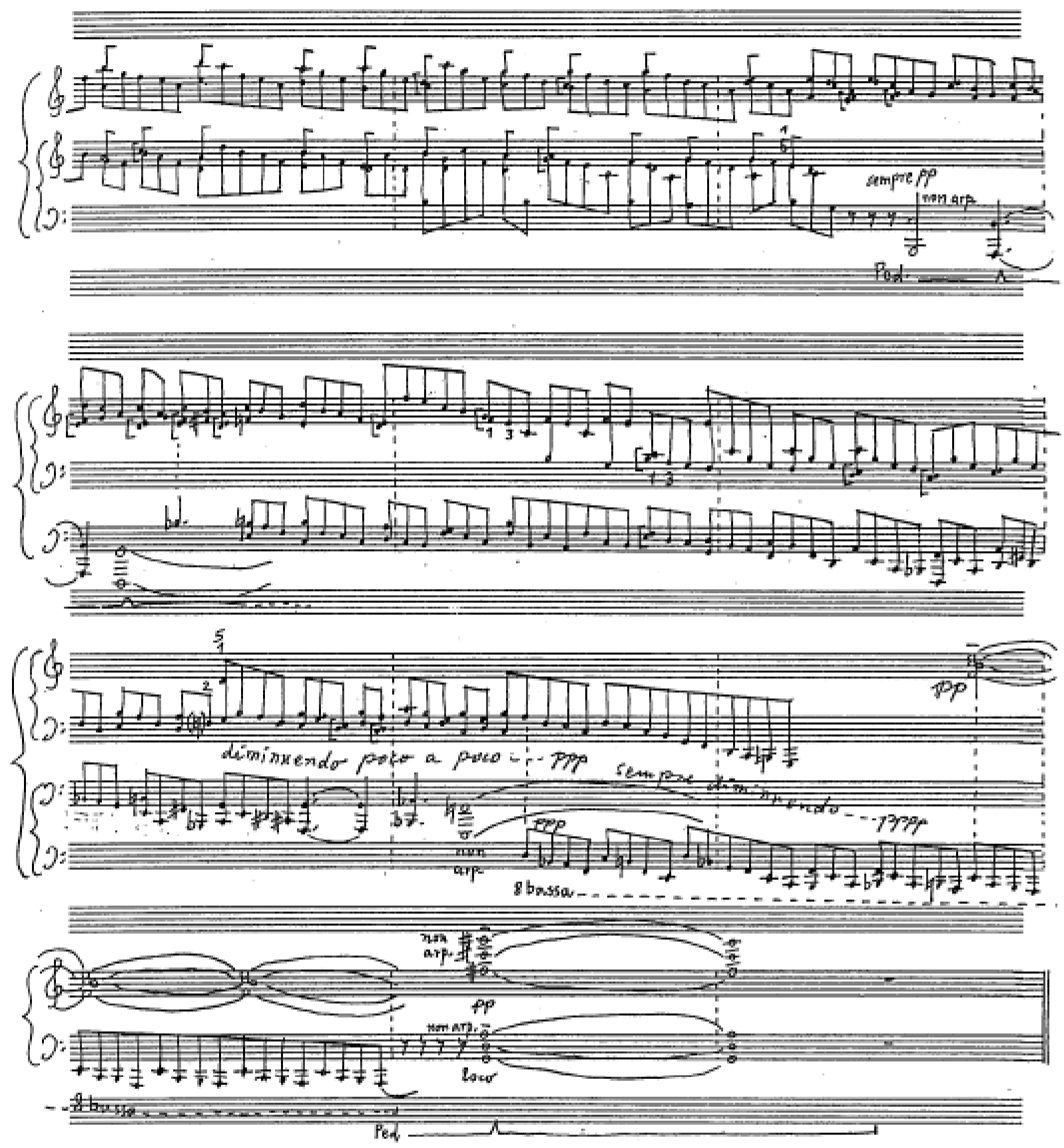